\title{
Correlation between Pre-Service Teachers' Information Technology Integration Attitude and Creative Teaching Behavior
}

\author{
Cheng-Ping Chang1, I-Jun Chen ${ }^{2}$ \\ ${ }^{1}$ Department of Education, National University of Tainan \\ ${ }^{2}$ Department of Psychology, College of Education, Soochow University \\ Email: justin23@mail.nutn.edu.tw, herb.ij@gmail.com
}

Received 19 August 2015; accepted 27 September 2015; published 30 September 2015

Copyright (C) 2015 by authors and Scientific Research Publishing Inc.

This work is licensed under the Creative Commons Attribution International License (CC BY). http://creativecommons.org/licenses/by/4.0/

(c) (i) Open Access

\begin{abstract}
This study aims to explore pre-service teachers' attitude toward information technology based instruction and creative teaching behavior and their relationship. This study treated current teacher education students in National University of Tainan as subjects. As to research method, questionnaire was the tool of measurement. After eliminating invalid questionnaires with significant intention and incomplete responses, the researcher obtained 206 valid questionnaires. Valid return rate was $\mathbf{8 5 . 8 \%}$. Research findings are shown that there is a significant and positive correlation between information technology integration attitude and creative teaching behavior. Information technology integration attitude significantly predicts creative Teaching Behavior.
\end{abstract}

\section{Keywords}

Pre-Service Teachers, Information Technology Integration Attitude, Creative Teaching Behavior

\section{Introduction}

Human beings have turned from times of industrial revolution to information revolution. Economic development in Taiwan also changes from past labor-intensive orientation to knowledge economy. In order to enhance national competitiveness, governments of different countries have recognized the importance of creativity. Schools are the main institutes to cultivate future talents for the country and they play significant roles to enhance national economic and social development and be responsible for national creativity development and cultivation. Hence, in "The White Paper on Creative Education” announced in 2002, Ministry of Education (MOE) has developed the vision of Taiwan as Republic of Creativity and implemented "medium-range development program 
of creativity education”. Pre-education of creativity of “cultivation of creative students, creative teachers' growth, total construction of creative school, national proposal of creative lives, database of creativity learning and continuous cultivation of creative literacy" were thus launched (MOE, 2002); in 2005-2008, educational policy proposed the vision of "Creative Taiwan and Global Planning: Cultivation of People with Different Talents" and encouraged school instruction to treat the stimulation of students' creativity as the priority to actively participate in international competition and international society (MOE, 2004). It demonstrates importance of creativity development for the government.

As to development and enhancement of students' creativity, many studies (Beghetto \& Kaufman, 2011; Lin, 2011; Schacter \& Thum, 2004) demonstrated that teachers' Creative Teaching Behavior can enhance students' creativity. Creative instruction can trigger students' creativity and students can make progress in creative cognition, affection and ability. It will also enhance their capacities related to creativity: imagination, association, thinking ability, sense of humor and creative techniques. Hanushek (2002) and Sawyer (2011) demonstrated that in creative instruction, students made progress in multiple, new and effective science creation. Based on above, teachers' Creative Teaching Behavior is important for students' creativity development.

In addition, with the rapid change of information technology, education encounters significant reform of globalization and marketization which lead to unprecedented impact on educational circle. It significantly influences modern human society and life. With the development of information technology, school education can no long instruct modern students by traditional methods and it should respond to future works and lives with increasing amount of knowledge. Instructional tools change from blackboard, projector and TV to computer and internet (Chen, 2002; Buckingham, 2013). In 21 ${ }^{\text {st }}$ century, progress of information technology will lead to vigorous development of educational technology. Instructional activities and instructional quality have new prospect. Hence, teaching materials which could not be presented in the past can be demonstrated. Instruction and learning are carried out (Koehler \& Mishra, 2009). New generation becomes more competent to new challenge in the century. For teachers' instruction, use of internet and powerful calculation and communication capacity of computer and internet develop richer and immediate information and knowledge sources beyond teachers and textbooks in classrooms. Instructional models become inspiring, interactive and independent learning. Regarding students' learning, it can cultivate students' capacity and habit to use information tools. By learning in instructional environment of information technology, it can develop students' ability to search for and integrate knowledge, improve disadvantages of traditional instructional methods. Hence, traditional instructional methods and learning model can no longer help students adapt to modern and future lives (Shou, 2001).

With the prevalence of internet information, how to focus on students by digital technology, integrate technology and educational resources and introduce digital technology in instructional activities to enhance instructional and learning effectiveness is the new trend for different countries in the world to implement educational reform and upgrade educational quality. Therefore, e-learning based on information technology in different subjects of courses will be future tendency. It is the challenge of new times which will teachers must encounter. In instructional process, they should practice different instructional strategies according to students' backgrounds. After information technology based instruction was launched by Grade 1 - 9 Curriculum, one of the indicators of blueprint of information education is to ask teachers to spend at least $20 \%$ time on information technology based instruction.

As to teachers' technology based instruction, scholars mostly defined it by usage of instructional technology. For instance, in US virtual game Second Life is commonly applied in higher education. Schools of higher education are authorized to purchase private islands in virtual environment to allow students to have virtual reality learning. By the course, students are taught to construct and management their virtual world. Learners can have realistic learning experience and enhance learners' learning effectiveness (Trotter, 2008). Pena-Shaff et al. (2001) adopted group learning in the course and combined non-simultaneous BBS for self-reflection, inference, demonstration and construction to enhance independent group; Soloway et al. (2001) applied mobile device in courses. All students could have hand-held computers. Since hand-held computers are mobile, flexible and accessible, students can participate in highly cooperative activities in any places and at any time. With changeable technology, technology application in instruction is also wide and diverse. For teachers, information technology based instruction is the best solution to improve instructional methods and instructional skills. It also allows teachers to solve instructional problems or have creative instruction (Craft, 2011; Kzenek \& Christensen, 2008). Regarding information technology based instructional activities, most of students have positive attitude toward the instructional methods and course planning (Ku \& Lohr, 2003). According to research of Tanti and Moran 
(2009), Tsai, Chuang, Liang, \& Tsai (2011), learners mostly have positive attitude toward technology application in instruction.

However, sufficient information situations do not guarantee prominent educational effectiveness of combination between information technology and subjects since teachers should have solid information technology integration instructional capacity and attitude. As the keys in education, teachers' information integration instructional capacity and attitude will significantly influence information technology based instruction (Yin, 2003). Integration of information technology in instruction of different subjects will be one of the principal policies in the future to improve instructional models in schools. In addition, according to research, teachers' different capacities of information technology integration instruction and different information attitude toward instructional environment factors of information technology will influence their innovative behavior to apply information technology in instruction (Huang, 2005). Nowadays, governmental institutions and educational authority actively improve information devices and internet environment. If teachers lack instructional capacity to integrate information technology, they will resist creative instruction by information technology. Currently, the government invests in great amount of funds and actively implements information education. Are teachers' capacity and attitude of information technology based instruction enhanced? It is worthy of further study (Chang, Chu, \& Hsu, 2007). Teacher education universities aim to cultivate freshmen of education. However, in the period of teacher education, acceptance of concepts of information education, capacity to apply information technology, ability of information technology based instruction and attitude toward information technology based instruction are the key factors of modern implementation of information education. Hence, actual observation of pre-service teachers' capacity and attitude toward information technology based instruction will enhance the practice of information education.

Based on above, enhancement of teachers' capacity and attitude of information technology based instruction is the focus of national key policy and educational reform. It more properly transforms and presents teaching materials, provides multiple instructional methods, enhances connection between teachers and students, enriches resources and considerably enhances feasibility of creative instruction. However, previous research focused on teachers' information literacy and lack of hardware facilities. Few studies probed into correlation between pre-service teachers' information technology integration attitude and Creative Teaching Behavior. Therefore, this study aims to explore pre-service teachers' attitude toward information technology based instruction and Creative Teaching Behavior and their relationship. Finally, the findings will serve as reference for teacher education institutes to plan courses related to information technology. The researcher will propose suggestions for implementation of information technology based instruction.

\section{Literature Review}

\subsection{Information Integration Attitude}

In past research, researchers had different definitions and views on information based instruction. However, they mostly interpreted the significance of information technology by computer and internet technology. This study defines it as new information technology upon computers and internet and it is applied to instructional activities in order to enhance students' meaningful learning in the courses. It integrates learning fields and cultivates students' capacity to use technology and information.

In many empirical studies, information technology has been treated as the tool to effectively enhance instruction and learning. Buckingham (2013) suggested that for students, in comparison to traditional classrooms, computer classroom learning is more effective and the students were highly satisfied. They enjoyed interaction, discussion and multimedia presentation in computer classrooms. Information based instruction can trigger students' learning motive and draw their attention. Hence, they will be more concentrated on teachers' instruction. Information technology usually launches students' dialogue, discussion, learning and experience sharing. Hence, peer interaction increases and it cultivates students' affective skills. Such collaborative learning tends to lead to wisdom. After implementation of information based instruction, teachers' instructional beliefs change. Instruction is no long the giving and receiving. Learning process should be active, creative and socially interactive. Knowledge is not transferred to students rigidly. Students actively construct knowledge. Hence, in higher level of information technology based instruction, it adopts instructional methods upon students learning.

Information technology is integrated in courses, teaching materials and instruction. Thus, technology becomes indispensable instructional and learning tool for teachers and students. In other words, technology use becomes 
part of daily lives in classrooms. Information technology can be extended as a method or procedure and search for solution at any time and in any places (Ertmer \& Ottenbreit-Leftwich, 2010; Galloway, 2011; Inan \& Lowther, 2010). For modern educational workers, information technology integration in instruction of different subjects is the trend of current school instruction. To catch up with the trend, MOE actively promoted information technology based instruction, cultivated literacy of secondary and elementary school teachers' information technology instruction, enhanced instructional software and teaching materials and constructed seeded schools of information (Lou, 2009).

Soner (2000) invested 114 pre-service teachers in University of Southern California and probed into their computer attitude and use after taking computer courses. The findings demonstrated that after computer related courses, pre-service teachers' attitude toward computer use became positive and active. According to study of Kinzie (1991), more computer training and experience would directly influence teachers' confidence and attitude toward computers. It further affected their actual adoption and introduction of computers in instruction. Therefore, Beaver (1990) and Oke (1992) suggested that computer literacy training in pre-service teacher education is critical.

In addition, the National Council for Accreditation of Teacher Education (NCATE), institute of teacher certification in US, realized the importance that technology instruction teachers should have technology instructional capacity. Thus, teachers can effectively and efficiently support instruction and learning by information technology and respond to technology instruction in the $21^{\text {st }}$ century. It suggested that teachers must have new recognition, new instructional methods, new role, new professional development and new attitude (NCATE, 1997). Standard of International Society for Technology in Education (ISTE, 2002) indicates teachers’ basic computer/technology operation and essential capacity of personal and professional development and instruction. Many teacher education institutes follow the standard, adjust the courses and include technology based instruction and learning in training for pre-service teachers. Ouyang, Yin, \& Chang (2007) suggested that information technology integration courses can enhance capacity of pre-service teachers in teacher education universities to integrate information technology in instruction. Teacher education courses must teach future teachers to appropriately apply information technology in instruction and learning in order to catch up with changeable technology. Gillingham and Topper (1999) proposed four feasible measures in teacher education institutes for teaching pre-service teachers to adopt information technology: 1) One of courses in teacher education institutes is designed upon information technology. Teacher who is familiar with technology and pedagogy is responsible for the instruction; 2) by penetration; perspective of information technology is included in each course of teacher education. The method is the most effective for experts of subjects. Hence, teachers in teacher education institutes will focus on knowledge of subjects and how to apply technology in the subjects; 3) students, instead of teachers, are responsible for knowledge of learning information technology. Students select their familiar content and they do not have to learn the content they already taken. They will focus on knowledge to apply technology; 4) by case study, based on classroom knowledge and analytical practice; it allows students to explore some cases of information technology based instruction in order to help teacher education students apply different kinds of information technology in instruction and learning with efficacy and efficiency. Ouyang, Yin, \& Chang (2007) suggested that in order to effectively use technology in future instruction, pre-service teachers should learn from teacher education institutes to integrate information in instruction. The objective is to provide students with more opportunities of real instructional experience. Hence, students can practice information based instruction. In the period of teacher education, acceptance of concepts of information education, application of information capacity, ability of information technology based instruction and attitude toward information technology based instruction are the key factors to implement current information education. By observing preservice teachers' attitude toward information technology based instruction, we will be able to implement information education.

\subsection{Creative Teaching Behavior}

What is Creative teaching behavior? Simonton (2012) suggested that Creative teaching behavior means in instructional process, teachers adopt multiple and interesting measures and rich content to trigger students' internal learning motivation. It cultivates students’ learning attitude and enhances students’ learning ability. According to Lamb \& Johnson (2010), creative instruction means teachers are creative in instructional process and adopts various instructional methods or strategies to create innovative instruction to enhance students' concen- 
tration and inspire and enhance students' creativity, imagination and learning motivation. Bramwell, Reilly, Lilly, Kronish, \& Chennabathni (2011) suggested that when teachers solve instructional problems by personal creative thoughts and teach knowledge and capacity to students by designing activities with instructional value, it is called Creative Teaching Behavior. Craft (2011) indicated that Creative Teaching Behavior is the demonstration of teachers' creativity. Teachers solve problems of instructional plans and practice by creativity or creative thinking in order to accomplish educational goals. Creative Teaching Behavior is defined as instructional measure or activity of teachers who develop the ideas, plan and use new instruction to more effectively accomplish educational objectives. Rinkevich (2011) suggested that Creative Teaching Behavior means in instructional planning, implementation and evaluation, teachers help students have meaningful learning by new, appropriate and valuable instruction. By new and old knowledge and experience and various new, proper and valuable strategies, materials, activities and situations, teachers enhance students learning motive, cultivate students' knowledge, capacity, attitude or skill of learning.

In addition, as to creative instructional strategies, many studies demonstrated specific findings. Sternberg (1996) proposed concrete creative instructional strategies: 1) propose the model of creative role; 2) encourage question on hypotheses; 3) allow mistakes; 4) encourage adventure; 5) allow students to establish the items and design plans; 6) evaluate creative research projects; 7) encourage creative ideas and products; 8) provide thinking time; 9) tolerate ambiguity; 10) indicate the obstacles encountered by creative thinkers; 11) encourage active growth; 12) know and create environment for creative thinking. Schacter, Califano, Bock, \& Bendotti (2002) suggested that instructional strategies mean all measures adopted by teachers in instructional activities to guide students' learning with plans and accomplish instructional goals. Tseng (2004: p. 18) has proposed five creative instructional strategies: 1) create suitable learning environment; 2) use modern information technology and various instructional methods; 3 ) encourage students to develop interest, explore environment, have adventure and discover problems; 4) provide thinking time, tolerate mistakes and different opinions in order to trigger more hypotheses; 5) enhance activities with hands and mind and encourage students to have meta-thinking; among others, "use modern information technology and various instructional methods" is the focus of this study. According to Innovation Diffusion Theory of Rogers (2003), teachers' intention to properly use information technology is associated with the factors of their adoption of it. Based on research of He (2002), teachers' application of information technology based instruction can increase students' learning effectiveness. Hence, learning can be diverse, personalized and interesting. It is the best option and tool for teachers to improve instructional methods and instructional skills. In addition, Kamariah et al. (2010) suggested that in the past decades, integration between information technology and educational system has become the focus in school education. Information technology is found effective to enhance instruction and learning. Information technology integration in instruction of different fields becomes the mainstream of future learning. Teachers should be continuously innovative in instructional experience, course design, teaching materials \& methods and instructional evaluation. If teachers can use information technology for instructional innovation, they will effectively enhance instructional and learning quality (Tseng, 2012; Lou, 2009).

\section{Research Method}

\subsection{Research Hypotheses}

According to literature review, exploration and inference, this study proposes the following hypotheses:

$\mathrm{H1}$ : Information technology integration attitude is significantly and positively related to future creative teaching behavior.

H2: Information technology integration attitude significantly predicts future Creative Teaching Behavior.

\subsection{Research Subjects and Sampling Design}

This study treated current teacher education students in National University of Tainan as subjects. As to research method, questionnaire was the tool of measurement. It was based on pretest and formal questionnaires. Scoring was upon Likert-type 5-point scale. "Strongly agree”, "agree”, "neutral”, “disagree” and "strongly disagree” refer to $5-1$. With reverse questions, the scoring is reverse. This study first validated the scale and the items were based on expert validity, item analysis, factor analysis and reliability analysis. Formal questionnaire was accomplished by eliminating some items. Questionnaires were retrieved by written questionnaires of convenience 
sampling. From November 4 to 6, 2014, 100 pretest written questionnaires were distributed and retrieved. Return rate was 82\%. There were 82 valid questionnaires; from November 11 to 15, formal questionnaires were distributed and retrieved. There were 240 formal questionnaires. After eliminating invalid questionnaires with significant intention and incomplete responses, the researcher obtained 206 valid questionnaires. Valid return rate was $85.8 \%$.

\subsection{Research Tools}

Variables measured by questionnaire include information integration attitude and Creative Teaching Behavior. Tool design includes subjects' demographic variables. Design of questionnaire, according to scales, measurement, dimensions and items, is shown as follows.

\section{Subjects' Demographic Variables}

As to demographic variables, since gender and grade are associated with the subjects. Demographic variables of this study include gender and grade, as shown below:

1) Gender: male and female; 2 categories.

2) Grade: freshman, sophomore, junior and senior; 4 categories.

\subsection{Validity and Reliability of Research Tools}

\subsubsection{Item Analysis}

As to item analysis, the researcher selects items by Critical Ratio (CR) of groups of high and low scores and result of correlation analysis on items. First, items are selected by CR. The researcher calculates total scores of items and selects the first $27 \%$ as the group of high score and $27 \%$ as the group of low score for t test of independent samples in order to find significant difference on the items. When CR is higher, it means the discrimination of items is better. Items with significant difference $(p<.05)$ are kept. By correlation analysis, the researcher tries to find the correlation between variable sand items. Based on correlation coefficients, the researcher keeps items with significant correlation and correlation coefficients >.3 (Wu \& Tu, 2010).

1) Creative teaching behavior

According to item analysis result of pretest questionnaire on Creative teaching behavior, CR of items are 5.982 - 11.158 and they are significantly different. It means that the items reveal positive discrimination. Based on correlation coefficient result of variable score and item score, correlation coefficients are .612 - .854 and they are >.3. According to result of CR and correlation coefficients, all items are kept.

2) Information technology integration attitude

According to item analysis result of pretest questionnaire on Information technology integration attitude, CR of items are 4.243 - 11.449 and they are significantly different. It means that the items reveal positive discrimination. Based on correlation coefficient result of variable score and item score, correlation coefficients are .322 - .820 and they are >.3. According to result of CR and correlation coefficients, all items are kept.

\subsubsection{Validity and Reliability Analysis}

As to validity analysis of scale, since variable connection and theoretical base of this study (Wu, 2008) are at the stage of primary exploration, by exploratory factor analysis (EFA), the researcher extracts suitable dimensions and items.

1) Scale of Creative Teaching Behavior

After EFA, Kaiser-Meyer-Olkin (KMO) of descriptive statistics is the mean between correlation coefficient and net correlation coefficient (Chiou, 2010). KMO of scale of Creative Teaching Behavior is .915 and it is close to 1. It means correlation coefficient is good and factor analysis can be conducted (Li, 2011). Approximate chi-square value of Bartlett test is 1843.246 and it is significantly different and significantly more than 0 . It means there are common factors between items and factor analysis can be conducted (Li, 2011). Hence, factor analysis is conducted on all items of variables. Factors are extracted by principle axis factors. According to related literatures, number of common factors extracted is decided (Li, 2011). In this study, it is designed by four dimensions of literature. In factor analysis, number of extracted factors is 4 (Wu, 2008). Rotation is based on orthogonal varimax. Thus, after rotation, factor loading difference of common factors of items is the highest (Wu, 2006). 
By EFA result, the researcher confirms items of four dimensions. Factor loading of 8 items of Factor 1 is .488 - .782. Factor loading of 5 items of Factor 2 is .577 - .781. Factor loading of 4 items of Factor 3 is .545 - .731. Factor loading of 3 items of Factor 4 is .544 - .594. They are more than standard .3. Accumulated explained variance is $67.940 \%$ and it means the scale has good validity. According to meanings of items of the factors, Factor 1, with 8 items, is named "multiple instructions are challenging”, Factor 2, with 5 items, is called "openminded meaningful learning”, Factor 3, with 4 items, is called "image thinking triggers imagination” and Factor 4, with 3 items, is called "independent learning of discussion and interaction”.

After factor analysis, in order to find the reliability of scale, the researcher conducts reliability analysis (Li, 2011). By $\alpha$ analysis of dimensions and variables of questionnaire, this study judges internal consistency of research tools. This study conducts reliability analysis by Cronbach's $\alpha$. When correlation between items of dimensions or variables is higher, consistency will be more significant. As to reliability analytical result of the scale, $\alpha$ of "multiple instructions are challenging" is $.935, \alpha$ of "open-minded meaningful learning" is $.906, \alpha$ of "image thinking triggers imagination" is .861 and $\alpha$ of "independent learning of discussion and interaction" is .795. Total $\alpha$ of future Creative Teaching Behavior is .959. It means the scale has good reliability.

2) Scale of information technology integration attitude

After EFA, Kaiser-Meyer-Olkin (KMO) of descriptive statistics is the mean between correlation coefficient and net correlation coefficient (Chiou, 2010). KMO of scale of information technology integration attitude is .913 and it is close to 1 . It means correlation coefficient is good and factor analysis can be conducted (Li, 2011). Approximate chi-square value of Bartlett test is 1056.387 and it is significantly different and significantly more than 0. It means there are common factors between items and factor analysis can be conducted (Li, 2011). Hence, factor analysis is conducted on all items of variables. Factors are extracted by principle axis factors. According to related literatures, number of common factors extracted is decided (Li, 2011). In this study, it is designed by four dimensions of literature. In factor analysis, number of extracted factors is 3 (Wu, 2008). Rotation is based on orthogonal varimax. Thus, after rotation, factor loading difference of common factors of items is the highest (Wu, 2006).

By EFA result, the researcher confirms items of four dimensions. Factor loading of 11 items of Factor 1 is .569 - .835. Factor loading of 2 items of Factor 2 is .739 - .746. Factor loading of 2 items of Factor 3 is .712 - .790. They are more than standard .3. Accumulated explained variance is $61.823 \%$ and it means the scale has good validity. According to meanings of items of the factors, Factor 1, with 8 items, is named "behavior", Factor 2, with 5 items, is called "cognition", Factor 3, with 4 items, is called "affection".

After factor analysis, in order to find the reliability of scale, the researcher conducts reliability analysis (Li, 2011). By $\alpha$ analysis of dimensions and variables of questionnaire, this study judges internal consistency of research tools. This study conducts reliability analysis by Cronbach's $\alpha$. When correlation between items of dimensions or variables is higher, consistency will be more significant. As to reliability analytical result of the scale, $\alpha$ of "multiple instructions are challenging" is .939, $\alpha$ of "open-minded meaningful learning" is .906, $\alpha$ of "image thinking triggers imagination" is .821 and $\alpha$ of "independent learning of discussion and interaction" is .728. Total $\alpha$ of future Creative Teaching Behavior is .920. It means the scale has good reliability.

\subsection{Data Analysis Methods}

This study used documentary analysis and questionnaire survey to analyze data, which are described as follows:

1) Documentary Analysis:

The literature and data concerning this study were collected, arranged, analyzed, generalized and integrated as the theoretical foundation of this study to develop the research framework, as well as to screen out the scales required in this study for testing.

2) Questionnaire Survey:

This study summarized relevant questionnaires to develop the pre-test questionnaire. After the pre-test questionnaires were returned, expert validity, item analysis and reliability analysis were used to revise relevant items, in order to develop the formal questionnaire as the tool for questionnaire survey. The data were analyzed based on the results of the questionnaire survey, and proposed relevant suggestions according to the analysis results. The statistical software SPSS19.0 was used to analyze the data of the returned questionnaires. Relevant statistical analyses were performed to meet the needs of the research purpose and various research hypothesis tests. The explanations are given as follows: 


\section{Descriptive Statistics}

The subjects' personal background variables were investigated using the analysis on personal basic information. This study used arithmetic average, standard deviation, percentage, and valid percent, to describe the structural characteristics of the subjects.

2. Reliability Analysis

This study used Cronbach's $\alpha$ coefficient to understand the reliability of each scale, tested the internal consistency of various dimensions to understand their internal consistency. The so-called reliability refers to the credibility and stability of a test, namely, the score of a test of the same group will reach consistency if they undergo the test for many times.

3. Correlational Analysis

Dual-variable data were used to test the correlation and prediction-related issues. Correlation analysis was used to investigate the relationship between two variables, as well as to test the relationship among various dimensions. This study used Pearson product-moment correlation analysis to test the correlation coefficients of different variables, to investigate whether there is a correlation among variables. In addition, this study also analyzed the correlation intensity for the subsequent repression analysis.

\section{Results Analysis and Discussion}

According to result of questionnaire survey, research purpose and hypotheses, the researcher conducts statistical analysis and discussion in order to find the relationship between information technology integration attitude and Creative Teaching Behavior, as shown below.

\subsection{Frequency Distribution of Demographic Variables}

In retrieved samples of formal questionnaire, demographic variables include gender and grade. As to gender, 46 are males (22.3\%) and 160 are females (77.7\%); as to grade, 72 subjects are freshmen (35.0\%), 24 are sophomores (11.7\%), 57 are juniors (27.7\%) and 53 are seniors (25.7\%).

\subsection{Correlation Analysis Result of Dimensions of Information Technology Integration Attitude and Dimensions of Creative Teaching Behavior}

According to descriptive statistics, the researcher calculates means and standard deviations of dimensions of variables, as shown in Table 1. Means are 3.352-3.833 and standard deviations are .629 - .943. By Pearson product-moment correlation, this study probes into correlation between dimensions of information technology integration attitude and dimensions of Creative Teaching Behavior, as shown in Table 1. Only affection $\mathrm{X}_{3}$ and “open-minded meaningful learning” $\mathrm{Y}_{2}$ do not have significant and positive correlation $(\mathrm{r}=.092, p>.05)$. Therefore, H1-6 “affection $\mathrm{X}_{3}$ and 'open-minded meaningful learning' $\mathrm{Y}_{2}$ have significant and positive correlation” is not supported. Sub-hypotheses of other dimensions show significant and positive correlation.

\subsection{Regression Analysis Result between Dimensions of Information Technology Integration Attitude and Dimensions of Creative Teaching Behavior}

In this study, independent variable, information technology integration attitude, is divided into "behavior $\mathrm{X}_{1}$ ”, “cognition $\mathrm{X}_{2}$ " and "affection $\mathrm{X}_{3}$ ”. Dependent variable, Creative Teaching Behavior, is divided into "multiple instructions are challenging $\mathrm{Y}_{1}$ ”, “open-minded meaningful learning $\mathrm{Y}_{2}$ ”, "image thinking triggers imagination $\mathrm{Y}_{3}$ ” and “independent learning of discussion and interaction $\mathrm{Y}_{4}$ ”. By stepwise regression analysis, this study probes into prediction of dimensions of independent variable, information technology integration attitude on dimensions of dependent variable, Creative Teaching Behavior.

\subsubsection{Prediction of Behavior $\mathrm{X}_{1}$, Cognition $\mathrm{X}_{2}$ and Affection $\mathrm{X}_{3}$ on "Multiple Instructions Are Challenging" $\mathrm{Y}_{1}$}

As shown in Table 2, stepwise regression analysis result of behavior $\mathrm{X}_{1}$, cognition $\mathrm{X}_{2}$ and affection $\mathrm{X}_{3}$ on multiple instructions are challenging $\mathrm{Y}_{1}$ shows that $\mathrm{F}$ value of behavior $\mathrm{X}_{1}$ is 58.398 and $p$ values is .000. They are significant. $\mathrm{B}$ is .472 and $p$ is .000 and they are significant. Coefficient of determination $\mathrm{R}^{2}$ of model is .223. In other words, prediction explained power of behavior $\mathrm{X}_{1}$ on "multiple instructions are challenging” $\mathrm{Y}_{1}$ is $22.3 \%$; 
Table 1. The means and standard deviations of dimensions of variables $(N=206)$.

\begin{tabular}{cccccccccc}
\hline & Means & $\begin{array}{c}\text { Standard } \\
\text { deviations }\end{array}$ & $\mathrm{Y}_{1}$ & $\mathrm{Y}_{2}$ & $\mathrm{Y}_{3}$ & $\mathrm{Y}_{4}$ & $\mathrm{X}_{1}$ & $\mathrm{X}_{2}$ & $\mathrm{X}_{3}$ \\
\hline $\mathrm{Y}_{1}$ & 3.649 & .678 & 1 & & & & & & \\
$\mathrm{Y}_{2}$ & 3.352 & .632 & $.717^{*}$ & 1 & & & & \\
$\mathrm{Y}_{3}$ & 3.784 & .629 & $.812^{*}$ & $.752^{*}$ & 1 & & & \\
$\mathrm{Y}_{4}$ & 3.744 & .736 & $.764^{*}$ & $.677^{*}$ & $.746^{*}$ & 1 & & & \\
$\mathrm{X}_{1}$ & 3.833 & .702 & $.472^{*}$ & $.347^{*}$ & $.452^{*}$ & $.428^{*}$ & 1 & & \\
$\mathrm{X}_{2}$ & 3.407 & .739 & $.331^{*}$ & $.320^{*}$ & $.359^{*}$ & $.274^{*}$ & $.601^{*}$ & 1 & \\
$\mathrm{X}_{3}$ & 3.473 & .943 & $.173^{*}$ & .092 & $.165^{*}$ & $.162^{*}$ & $.337^{*}$ & $.321^{*}$ & 1 \\
\hline
\end{tabular}

${ }^{*} p<.05$.

Table 2. Regression analysis result of behavior $X_{1}$, cognition $X_{2}$ and affection $X_{3}$ on multiple instructions are challenging $Y_{1}$.

\begin{tabular}{|c|c|c|c|c|c|c|c|}
\hline Steps & Variables & $\mathrm{R}^{2}$ & $\mathrm{R}^{2}$ change & F value & $\begin{array}{l}\text { Original regression } \\
\text { equation } \hat{\mathrm{Y}}_{1} \quad \text { (B) }\end{array}$ & $\begin{array}{c}\text { Standardized } \\
\text { regression equation } \\
\hat{\mathrm{Z}}_{\mathrm{y} 1}(\beta)\end{array}$ & $\mathrm{T}$ value \\
\hline & Constant & & & & $1.904^{*}$ & & \\
\hline 1 & $X_{1}$ & 223 & .223 & $58.398^{*}$ & $.455^{*}$ & $.472^{*}$ & $7.642^{*}$ \\
\hline
\end{tabular}

original regression equation is $\hat{\mathrm{Y}}_{1}=1.904+.455 \mathrm{X}_{1}$ and standardized regression equation is $\hat{\mathrm{Z}}_{\mathrm{y} 1}=.472 Z_{X 1}$. Hence, $\mathrm{H} 2-1$ "behavior $\mathrm{X}_{1}$ significantly predicts multiple instructions are challenging $\mathrm{Y}_{1}$ ” is supported.

\subsubsection{Prediction of Behavior $X_{1}$, Cognition $X_{2}$ and Affection $X_{3}$ on Open-Minded Meaningful Learning $\mathrm{Y}_{2}$}

As shown in Table 3 , stepwise regression analysis result of behavior $X_{1}$, cognition $X_{2}$ and affection $X_{3}$ on “open-minded meaningful learning” $\mathrm{Y}_{2}$ shows that $\mathrm{F}$ value of behavior $\mathrm{X}_{1}$ is 27.947 and $p$ value is .000 . They are significant. $\mathrm{B}$ is .242 and $p$ is .003 and they are significant. $\mathrm{F}$ value of cognition $\mathrm{X}_{2}$ is 4.585 and $p$ value is .033. They are significant. $\beta$ is .174 and $p$ is .033 and they are significant. Coefficient of determination $\mathrm{R}^{2}$ is .140. In other words, prediction explained power of behavior $\mathrm{X}_{1}$ and cognition $\mathrm{X}_{2}$ on open-minded meaningful learning $\mathrm{Y}_{2}$ is $14.0 \%$; original regression equation is $\hat{\mathrm{Y}}_{2}=2.009+.218 \mathrm{X}_{1}+.149 \mathrm{X}_{2}$ and standardized regression equation is $\hat{\mathrm{Z}}_{\mathrm{y} 2}=.242 \mathrm{Z}_{\mathrm{X} 1}+.174 \mathrm{Z}_{\mathrm{X} 2}$.

Therefore, H2-2 "behavior $\mathrm{X}_{1}$ and cognition $\mathrm{X}_{2}$ significantly predict open-minded meaningful learning $\mathrm{Y}_{2}$ ” is supported.

\subsubsection{Prediction of Behavior $X_{1}$, Cognition $X_{2}$ and Affection $X_{3}$ on Image Thinking Triggers Imagination $\mathrm{Y}_{3}$}

As shown in Table 4, stepwise regression analysis result of behavior $\mathrm{X}_{1}$, cognition $\mathrm{X}_{2}$ and affection $\mathrm{X}_{3}$ on image thinking triggers imagination $\mathrm{Y}_{3}$ shows that $\mathrm{F}$ value of behavior $\mathrm{X}_{1}$ is 52.497 and $p$ value is .000 . They are significant. $\beta$ is .452 and $p$ is 000 . They are significant. Coefficient of determination $\mathrm{R}^{2}$ of model is .205. In other words, prediction explained power of behavior $\mathrm{X}_{1}$ on image thinking triggers imagination $\mathrm{Y}_{3}$ is $20.5 \%$; original regression equation is $\hat{\mathrm{Y}}_{3}=2.230+.405 \mathrm{X}_{1}$, standardized regression equation is $\hat{\mathrm{Z}}_{\mathrm{y} 3}=.452 \mathrm{Z}_{\mathrm{X} 1}$. Thus, H2-3 "behavior $\mathrm{X}_{1}$ significantly predicts image thinking triggers imagination $\mathrm{Y}_{3}$ ” is supported.

\subsubsection{Prediction of Behavior $\mathrm{X}_{1}$, Cognition $\mathrm{X}_{2}$ and Affection $\mathrm{X}_{3}$ on Independent Learning of Discussion and Interaction $\mathrm{Y}_{4}$}

As shown in Table 5, stepwise regression analysis result of behavior $\mathrm{X}_{1}$, cognition $\mathrm{X}_{2}$ and affection $\mathrm{X}_{3}$ on independent learning of discussion and interaction $\mathrm{Y}_{4}$ shows that $\mathrm{F}$ value of behavior $\mathrm{X}_{1}$ is 45.867 and $p$ value is .000. They are significant. $\beta$ is .428 and $p$ is .000 . They are significant. Coefficient of determination $\mathrm{R}^{2}$ is .184 . In other words, prediction explained power of behavior $\mathrm{X}_{1}$ on independent learning of discussion and interaction 
Table 3. Regression analysis result of behavior $\mathrm{X}_{1}$, cognition $\mathrm{X}_{2}$ and affection $\mathrm{X}_{3}$ on “open-minded meaningful learning” $\mathrm{Y}_{2}$.

\begin{tabular}{|c|c|c|c|c|c|c|c|}
\hline Steps & Variables & $\mathrm{R}^{2}$ & $\mathrm{R}^{2}$ change & F value & $\begin{array}{l}\text { Original regression } \\
\text { equation } \hat{Y}_{1} \quad \text { (B) }\end{array}$ & $\begin{array}{c}\text { Standardized } \\
\text { regression equation } \\
\hat{\mathrm{Z}}_{\mathrm{y} 1} \quad(\beta)\end{array}$ & $\mathrm{T}$ value \\
\hline & Constant & & & & $2.009^{*}$ & & \\
\hline 1 & $\mathrm{X}_{1}$ & .120 & .120 & $27.947^{*}$ & $.218^{*}$ & $.242^{*}$ & $2.976^{*}$ \\
\hline 2 & $\mathrm{X}_{2}$ & .140 & .019 & $4.585^{*}$ & $.149^{*}$ & $.174^{*}$ & $2.141^{*}$ \\
\hline
\end{tabular}

Table 4. Regression analysis result of behavior $X_{1}$, cognition $X_{2}$ and affection $X_{3}$ on image thinking triggers imagination $Y_{3}$.

\begin{tabular}{|c|c|c|c|c|c|c|c|}
\hline Steps & Variables & $\mathrm{R}^{2}$ & $\mathrm{R}^{2}$ change & F value & $\begin{array}{l}\text { Original regression } \\
\text { equation } \hat{\mathrm{Y}}_{1} \quad(\mathrm{~B})\end{array}$ & $\begin{array}{c}\text { Standardized } \\
\text { regression equation } \\
\hat{\mathrm{Z}}_{\mathrm{y} 1} \quad(\beta)\end{array}$ & $\mathrm{T}$ value \\
\hline & Constant & & & & $2.230^{*}$ & & \\
\hline 1 & $\mathrm{X}_{1}$ & .205 & .205 & $52.497 *$ & $.405^{*}$ & $.452^{*}$ & $7.245^{*}$ \\
\hline
\end{tabular}

Table 5. Regression analysis result of behavior $\mathrm{X}_{1}$, cognition $\mathrm{X}_{2}$ and affection $\mathrm{X}_{3}$ on independent learning of discussion and interaction $\mathrm{Y}_{4}$.

\begin{tabular}{|c|c|c|c|c|c|c|c|}
\hline Steps & Variables & $\mathrm{R}^{2}$ & $\mathrm{R}^{2}$ change & F value & $\begin{array}{l}\text { Original regression } \\
\text { equation } \hat{Y}_{1} \text { (B) }\end{array}$ & $\begin{array}{c}\text { Standardized } \\
\text { regression equation } \\
\hat{\mathrm{Z}}_{\mathrm{y} 1} \quad(\beta)\end{array}$ & T value \\
\hline & Constant & & & & $2.023^{*}$ & & \\
\hline 1 & $\mathrm{X}_{1}$ & .184 & .184 & $45.867^{*}$ & $.449^{*}$ & $.428^{*}$ & $6.773^{*}$ \\
\hline
\end{tabular}

$\mathrm{Y}_{4}$ is 18.4\%; original regression equation is $\hat{\mathrm{Y}}_{4}=2.023+.449 \mathrm{X}_{1}$, standardized regression equation is $\hat{Z}_{\mathrm{y} 4}$ $=.428 \mathrm{Z}_{\mathrm{X} 1}$. Hence, $\mathrm{H} 2-4$ "behavior $\mathrm{X}_{1}$ significantly predicts independent learning of discussion and interaction $\mathrm{Y}_{4}$ ” is supported.

Stepwise regression analysis result of 3 dimensions of independent variable, information technology integration attitude, on 4 dimensions of dependent variable, Creative Teaching Behavior, is shown in Table 6.

\section{Conclusion and Suggestions}

This study probed into pre-service teachers' capacity and attitude of information technology based instruction and their correlation and prediction effect. Research findings are shown as follows:

1) Correlation between information technology integration attitude and Creative Teaching Behavior

Validation result of hypotheses on correlation between information technology integration attitude and Creative Teaching Behavior shows that except for affection and open-minded meaningful learning which do not have significant and positive correlation, other dimensions show significant and positive correlation. Generally speaking, there is a significant and positive correlation between information technology integration attitude and Creative Teaching Behavior.

\section{2) Prediction of information technology integration attitude on Creative Teaching Behavior}

This study realizes that information technology integration attitude significantly predicts Creative Teaching Behavior. Independent variable, information technology integration attitude, includes three dimensions: behavior, cognition and affection. Dependent variable, Creative Teaching Behavior, includes multiple instructions are challenging, open-minded meaningful learning, image thinking triggers imagination and independent learning of discussion and interaction. By stepwise regression analysis, this study probes into prediction of dimensions of independent variable, information technology integration attitude, on dimensions of dependent variable, Creative Teaching Behavior. According to the findings, behavior significantly predicts "multiple instructions are challenging”. Behavior and cognition significantly predict "open-minded meaningful learning”. Behavior significantly predicts image thinking triggers imagination. Behavior significantly predicts independent learning of discussion and interaction. 
Table 6. Regression analysis result of 3 dimensions of independent variable, information technology integration attitude, on 4 dimensions of dependent variable, creative teaching behavior.

\begin{tabular}{|c|c|c|c|c|c|c|c|c|}
\hline & \multicolumn{8}{|c|}{$\mathrm{Y}$} \\
\hline & \multicolumn{2}{|c|}{$\mathrm{Y}_{1}$} & \multicolumn{2}{|c|}{$\mathrm{Y}_{2}$} & \multicolumn{2}{|c|}{$\mathrm{Y}_{3}$} & \multicolumn{2}{|c|}{$\mathrm{Y}_{4}$} \\
\hline & B & $\beta$ & B & B & $\beta$ & $\beta$ & B & $\beta$ \\
\hline \multicolumn{9}{|l|}{$\mathrm{X}$} \\
\hline Constant & $1.904^{*}$ & & $2.009^{*}$ & & $2.230^{*}$ & & $2.023^{*}$ & \\
\hline $\mathrm{X}_{1}$ & $.455^{*}$ & $.472^{*}$ & $.218^{*}$ & $.242^{*}$ & $.405^{*}$ & $.452^{*}$ & $.449^{*}$ & $.428^{*}$ \\
\hline $\mathrm{X}_{2}$ & & .075 & $.149^{*}$ & $.174^{*}$ & & .136 & & .026 \\
\hline $\mathrm{X}_{3}$ & & .016 & & -.053 & & .014 & & .020 \\
\hline $\mathrm{R}^{2}$ & \multicolumn{2}{|c|}{.223} & \multicolumn{2}{|c|}{.140} & \multicolumn{2}{|c|}{.205} & \multicolumn{2}{|c|}{.184} \\
\hline$\Delta \mathrm{R}^{2}$ & \multicolumn{2}{|c|}{.219} & \multicolumn{2}{|c|}{.131} & \multicolumn{2}{|c|}{.201} & \multicolumn{2}{|c|}{.180} \\
\hline $\mathrm{F}$ & \multicolumn{2}{|c|}{$58.398^{*}$} & \multicolumn{2}{|c|}{$4.585^{*}$} & \multicolumn{2}{|c|}{$52.497^{*}$} & \multicolumn{2}{|c|}{$45.867^{*}$} \\
\hline
\end{tabular}

Hence, teacher education institutes should integrate information technology in courses of different subjects. It will be the future trend and challenge of new times teachers must encounter. In instructional process, teachers must practice different instructional strategies on students with different backgrounds. Teachers should have proper freedom, be encouraged and provided with sufficient resources. Peers of teachers can construct instructional study group. By discussion and interaction, they exchange the instructional experience. Enhancement of teachers' capacity and attitude of information technology based instruction are the keys of national policy and educational reform. It properly transforms and presents teaching materials, provides multiple instructional methods, enhances connection between teachers and students, enriches resources and significantly enhances feasibility of creative instruction.

\section{References}

Beaver, J. F. (1990). A Profile of Undergraduate Education Technology in Competence: Are We Preparing Today’s Education Graduates for Teaching in the 1990’s. ERIC ED 332985.

Beghetto, R. A., \& Kaufman, J. C. (2011). Teaching for Creativity with Disciplined Improvisation. In R. K. Sawyer (Ed.), Structure and Improvisation in Creative Teaching. New York: Cambridge University Press. http://dx.doi.org/10.1017/CBO9780511997105.006

Bramwell, G., Reilly, R. C., Lilly, F. R., Kronish, N., \& Chennabathni, R. (2011). Creative Teacher. Roeper Review, 33, 228-238. http://dx.doi.org/10.1080/02783193.2011.603111

Buckingham, D. (2013). Teaching the Creative Class? Media Education and the Media Industries in the Age of "Participatory Culture”. Journal of Media Practice, 14, 25-41. http://dx.doi.org/10.1386/jmpr.14.1.25 1

Chang, Y. F., Chu, C. Y., \& Hsu, C. L. (2007). The Current State of Elementary School Teachers’ Information Technology Integration into Instruction. Journal of Educational Media \& Library Sciences, 44, 413-434.

Chen, N. S. (2002). The Status of Important Concepts on e-Learning and Domestic Institutions of Learning Network. Conference on Network Learning. Taipei: National Taiwan Normal University.

Chiou, H. J. (2010). Quantitative Research and Statistical Analysis. Taipei: Wu-Nan Book.

Craft, A. (2011). Approaches to Creativity in Education in the United Kingdom. In J. Sefton-Green, P. Thomson, K. Jones, \& L. Bresler (Eds.), The Rutledge International Handbook of Creative Learning (pp. 129-139). New York, NY: Routledge.

Craft, A. (2011). Creativity and Education Futures: Learning in a Digital Age. Stoke-on-Trent: Trentham.

Ertmer, P., \& Ottenbreit-Leftwich, A. T. (2010). Teacher Technology Change: How Knowledge, Confidence, Beliefs and Culture Intersect. Journal of Research on Technology in Education, 42, 255-284. http://dx.doi.org/10.1080/15391523.2010.10782551

Galloway, J. P. (2011). Technology Education and Integration: A Position Paper on Attitude, Perspective and Commitment. 
http://jerrygalloway.com/papers/icte99.htm

Gillingham, M. G., \& Topper, A. (1999). Technology in Teacher Preparation: Preparing Teachers for the Future. http://ttp.ed.uic.edu/ttp/techprep.html

Hanushek, E. A. (2002). Teacher Quality. In L. T. Izumi, \& W. M. Evers (Eds.), Teacher Quality (pp. 1-12). Palo Alto, CA: Hoover Press.

He, R. G. (2002). Status and Development of Taiwan’s Information Education—The Information Technology into Teaching. Information and Education, 87, 22-48.

Huang, M. Z. (2005). A Research on Infusing Information Technology into Instructional Innovation Behavioral Intention of Kaohsiung County Elementary School Teachers. Unpublished Master's Thesis, Department of Industry Technology Education, National Kaohsiung Normal University, Kaohsiung.

Inan, F. A., \& Lowther, D. L. (2010). Factors Affecting Technology Integration in K-12 Classrooms: A Path Model. Educational Technology Research and Development, 58, 137-154. http://dx.doi.org/10.1007/s11423-009-9132-y

International Society for Technology in Education, ISTE (2002). ISTE National Educational Technology Standards and Performance Indicators. http://www.iste.org

Kamariah, A. T., Ahmad, M. A., Wong, S. L., \& Rohani, A. T. (2010). Exploring Secondary School Students’ Motivation Using Technologies in Teaching and Learning Mathematics. Procedia-Social and Behavioral Sciences, 2, 4650-4654. http://dx.doi.org/10.1016/j.sbspro.2010.03.744

Kinzie, M. B., \& Delcourt, M. A. B. (1991). Computer Technologies in Teacher Education: The Measurement of Attitudes and Self-Efficacy. Proceedings of the Annual Meeting of the American Educational Research Association, Chicago, 3-7 April 1991.

Koehler, M. J., \& Mishra, P. (2009). What Is Pedagogical Technological Content Knowledge. Contemporary Issues in Technology and Teacher Education, 9, 60-70.

Ku, H. Y., \& Lohr, L. L. (2003). A Case Study of Chinese Students’ Attitudes toward Their First Online Learning Experience. Educational Technology, Research and Development, 51, 95-102. http://dx.doi.org/10.1007/BF02504557

Kzenek, G., \& Christensen, R. (2008). The Importance of Computer Attitudes and Competencies in Primary and Secondary Schools. In J. Voogt, \& G. Kzenek (Eds.), International Handbook of Information Technology in Primary and Secondary Education (pp.321-328). New York: Springer.

Lamb, A., \& Johnson, L. (2010). Bring Back the Joy: Creative Teaching, Learning, and Librarianship. Teacher Librarian, 38, 61-66.

Li, J. Q. (2011). Easy to Use SPSS/PASW Statistical Analysis Practice. Taipei: Chuan Hwa Book.

Lin, Y. S. (2011). Fostering Creativity through Education: A Conceptual Framework of Creative Pedagogy. Creative Education, 2, 149-155. http://dx.doi.org/10.4236/ce.2011.23021

Lou, S. J. (2009). Information Technology Integration into Instruction. In Z. L. Tang (Ed.), Introduction of Education (pp. 309-328). Taipei: Wu-Nan Book.

Ministry of Education (2002). White Paper on Creative Education. Taipei: Ministry of Education.

Ministry of Education (2004). 2005-2008 Spindle Education Policy. Taipei: Ministry of Education.

National Council for Accreditation of Teacher Education (1997). Technology and the New Professional Teacher: Preparing for the 21st Century Classroom. http://www.ncate

Oke, L. (1992). The Need for Technology Instruction in Teacher Education. ERIC ED 352004.

Ouyang, Y., Yin, M. C., \& Chang, C. C. (2007). From Theory to Practice-The Curriculum Design and Learning Effects of Integrating Information Technology into Instruction for Pre-Service Teachers. Curriculum \& Instruction Quarterly, 10, 97-110.

Pena-Shaff, J., Martin, W., \& Gay, G. (2001). An Epistemological Framework for Analyzing Student Interactions in Computer-Mediated Communication Environments. Journal of Interactive Learning Research, 12, 41-68.

Rinkevich, J. R. (2011). Creative Teaching: Why It Matters and Where to Begin. The Clearing House, 84, 219-223. http://dx.doi.org/10.1080/00098655.2011.575416

Rogers, E. M. (2003). Diffusion of Innovation (5th ed.). New York: The Free Press.

Sawyer, R. K. (Ed.) (2011). Structure and Improvisation in Creative Teaching. New York: Cambridge University Press. http://dx.doi.org/10.1017/CBO9780511997105

Schacter, J., Califano, L., Bock, J., \& Bendotti, M. (2002). Quality Teachers: Defining and Developing Them. Instructional Leader, 15, 1-12.

Schacter, J., \& Thum, Y. M. (2004). Paying for High and Low Quality Teaching. Economics of Education Review, 23, 411- 
430. http://dx.doi.org/10.1016/j.econedurev.2003.08.002

Shou, T. W. (2001). Teaching of Information and Network. Taipei: Normal Bookstore.

Simonton, D. K. (2012). Teaching Creativity: Current Findings, Trends, and Controversies in the Psychology of Creativity. Teaching of Psychology, 39, 217-222. http://dx.doi.org/10.1177/0098628312450444

Soloway, E., Norris, C., Blumenfeld, P., Fishman, B., Krajcik, J., \& Marx, R. (2001). Log on Education: Handheld Devices Are Ready-at-Hand. Communications of the ACM, 44, 15-20. http://dx.doi.org/10.1145/376134.376140

Soner, Y. (2000). Effects of an Educational Computing Course on Preservice and In-Service Teachers: A Discussion and Analysis of Attitudes and Use. Journal of Research on Computing in Education, 32, 479-492. http://dx.doi.org/10.1080/08886504.2000.10782293

Sternberg, R. J. (1996). Cognitive Psychology. Orlando: Harcourt Brace \& Company.

Tanti, M., \& Moran, W. (2009). Warts and All: Integration ICT in Teacher Training. The International Journal of Learning, 16, 641-655.

Trotter, A. (2008). Educators Get a Second Life. Education Week, 27, 1-17.

Tsai, C. C., Chuang, S. C., Liang, J. C., \& Tsai, M. J. (2011). Self-Efficacy in Internet-Based Learning Environments: A Literature Review. Educational Technology \& Society, 14, 222-240.

Tseng, C. H. (2012). The Effect of Elementary School Teachers' Innovativeness on the Implementation of Information Technology Integrated Instruction. Journal of School Administrators Research Association, 78, 43-68.

Tseng, W. C. (2004). A Study on the Relations of Teacher's Creative Teaching, Students' Metacognition, Creativity and Problem-Solving Ability in Elementary School. Master's Thesis, Department of Education Curriculum and Instruction, National Kaohsiung Normal University, Kaohsiung.

Wu, M. L. (2006). SPSS Statistics Applied Learning Practice-Questionnaire Analysis and Applied Statistics. Taipei: Acore Digital.

Wu, M. L. (2008). The Practice of Multivariate Analysis. Taipei: Wu-Nan Book.

Yin, M. C. (2003). From the Implement of Educational Technology in Education to Investigate the Integrated Technology into Instruction. National Taipei Normal University Bulletin of Elementary Education, 16, 1-36. 